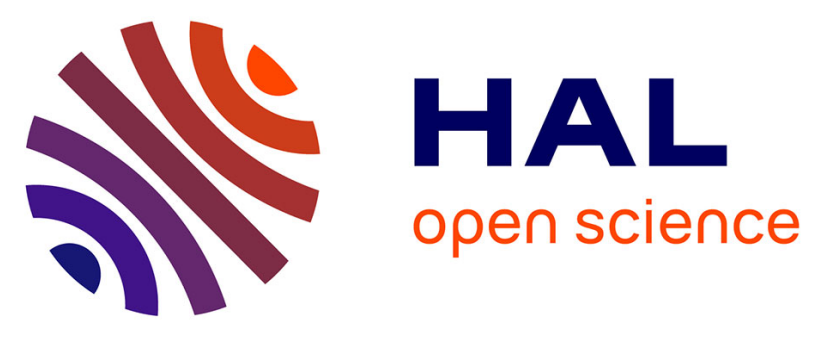

\title{
Microstructure aspects of radiation-cured networks: Cationically polymerized aromatic epoxy resins
}

\author{
Christelle Kowandy, Guillaume Ranoux, Marta Walo, Bertrand \\ Vissouvanadin, G. Teyssedre, Christian Laurent, Alexandre Berquand, \\ Michaël Molinari, Xavier Coqueret
}

\section{To cite this version:}

Christelle Kowandy, Guillaume Ranoux, Marta Walo, Bertrand Vissouvanadin, G. Teyssedre, et al.. Microstructure aspects of radiation-cured networks: Cationically polymerized aromatic epoxy resins. Radiation Physics and Chemistry, 2018, 143, pp.20-26. 10.1016/j.radphyschem.2017.09.006 . hal02009891

\section{HAL Id: hal-02009891 https://hal.univ-reims.fr/hal-02009891}

Submitted on 24 Nov 2020

HAL is a multi-disciplinary open access archive for the deposit and dissemination of scientific research documents, whether they are published or not. The documents may come from teaching and research institutions in France or abroad, or from public or private research centers.
L'archive ouverte pluridisciplinaire HAL, est destinée au dépôt et à la diffusion de documents scientifiques de niveau recherche, publiés ou non, émanant des établissements d'enseignement et de recherche français ou étrangers, des laboratoires publics ou privés. 
Manuscript submitted to Radiat. Phys. Chem. - IMRP 2016

\section{Microstructure aspects of radiation-cured networks: cationically polymerized aromatic epoxy resins}

Christelle Kowandy, ${ }^{\mathrm{a}}$ Guillaume Ranoux, ${ }^{\mathrm{a}}$ Marta Walo, ${ }^{\mathrm{b}}$ Bertrand Vissouvanadin, ${ }^{\mathrm{d}}$ Gilbert Teyssedre, ${ }^{\mathrm{d}}$ Christian Laurent, ${ }^{\mathrm{d}}$ Alexandre Berquand, ${ }^{\mathrm{c}}$ Michaël Molinari, ${ }^{\mathrm{c}}$ Xavier Coqueret ${ }^{\mathrm{a}, *}$

a Institut de Chimie Moléculaire de Reims, CNRS UMR 7312, Université de Reims Champagne-Ardenne, BP 1039, 51687 Reims, France

${ }^{\mathrm{b}}$ Institute of Nuclear Chemistry and Technology, Dorodna 16, 03-195 Warszawa, Poland

c Laboratoire de Recherche en Nanosciences, LRN EA 4682, Université de Reims Champagne-Ardenne, 21, rue Clément Ader, 51685 Reims, France

${ }^{\mathrm{d}}$ LAPLACE, UMR CNRS 5213, Université de Toulouse, 118 route de Narbonne, 31062 Toulouse, France

\section{* Corresponding author}

Contact: xavier.coqueret@univ-reims.fr - Tel/fax: +33 326913338

Abstract: The thermo-mechanical properties and nanostructural features of epoxy aromatic resins cationically cured by UV-visible or electron beam radiation have been studied by FTNIR spectroscopy, dynamic mechanical analysis (DMA), dielectric spectroscopy (DS), and atomic force microscopy (AFM). The influence of formulation (nature and content of onium salt) and of curing parameters (doses, thermal treatment) on the thermophysical have been investigated. The presence of several relaxation domains observed by DMA and DS analysis confirms the presence of heterogeneities in the cured materials. Network formation is described by the percolation of glassy nanoclusters which are evidenced by AFM analyses. AFM probing by quantitative nanomechanical measurements confirms the gradual build-up of the local Young's modulus in good agreement with the macroscopic value.

Keywords: cationic polymerization, aromatic epoxy monomers, glass transition, network properties, radiation curing, atomic force microscopy, dynamic mechanical thermal analysis, dielectric spectroscopy 


\section{Introduction}

Radiation-induced crosslinking-polymerization of multiacrylates yields highly crosslinked, heterogeneous networks (Di Lorenzo \& Seiffert, 2015) because of a complex chain-growth mechanism and chain kinetics (Bowman \& Kloxin, 2008) that have been studied for several decades (Dušek, 1971; Dušek et al., 1980). The recent development of experimental methods for probing materials at the nanoscale has made it possible to study more deeply the structural features of networks obtained by radiation-induced free radical processes. A general agreement for the description of the resulting material consists of a juxtaposition of highly crosslinked nanosized clusters interconnected by a continuous domain made of a weakly crosslinked polymer phase gradually driven to the glassy state (Krzeminski, 2010a; Krzeminski, 2010b).

The radiation-initiated cationic polymerization of epoxies and vinylethers continues to receive considerable interest since the original discovery of the potentialities of onium salts as initiators (Crivello et al., 1999). Onium salts with a low nucleophilicity counter anion can be activated by thermal, photochemical and radiochemical activation. Efficient Bronsted or Lewis acids are generated via different mechanisms and efficiently initiate the chain polymerization of epoxy functions or of other cationically polymerizable monomers (Coqueret, 2008; Ferry et al., 2016).

The assets of this chemistry continue to stimulate research on initiators systems and on application-oriented projects (Yağci \& Reetz, 1998; Sangermano, 2012; Przybytniak et al., 2016), but the current knowledge on the relations between reactivity, microstructure and properties is limited. In the frame of our current research on epoxy homopolymerization and its potentialities in the field of high performance composite materials and in nanolithography, we are currently investigating the thermal and microstructural aspects of the cationic polymerization. This present article reports on heterogeneity issues related to the radiationinitiated polymerization of model aromatic epoxies.

\section{Experimental}

\subsection{Materials}

Diglycidyl ether of bisphenol A, DGEBA (DER 330, Dow Chemical) and an epoxy novolac EPN (DEN 431, Dow Chemical) were the base model epoxy resins used in this study. The 


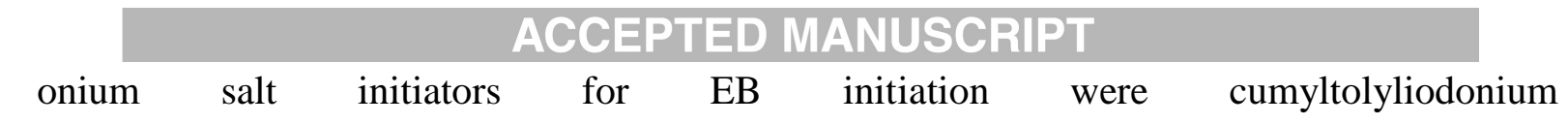
tetrakis(pentafluorophenyl)borate (Rhodorsil PI2074, Bluestar Silicone), named DAIS for diaryliodonium salt, and triarylsulfonium hexafluorophosphate (TASP) as a $50 \%$-wt solution in propylene carbonate (Sigma Aldrich). For visible light photo-activation an Iron(II) complex salt ( $\eta^{5}$-cyclopentadienyl) $\left(\eta^{6}\right.$-1-methyl-naphtalene)-iron(II) hexafluorophosphate (CpIS for cyclopentadienyl iron salt) was synthesized in our lab (Defoort et al., 2006). For UV-visible curing at $385 \mathrm{~nm}$, 2-isopropyl thioxanthone, ITX (Aldrich) was used a photosensitizer for DAIS. The desired amount of initiator was added to the resin and cautiously dissolved by mechanical stirring under exclusion of visible light. The samples were protected for moisture sorption at the different stages of their preparation.
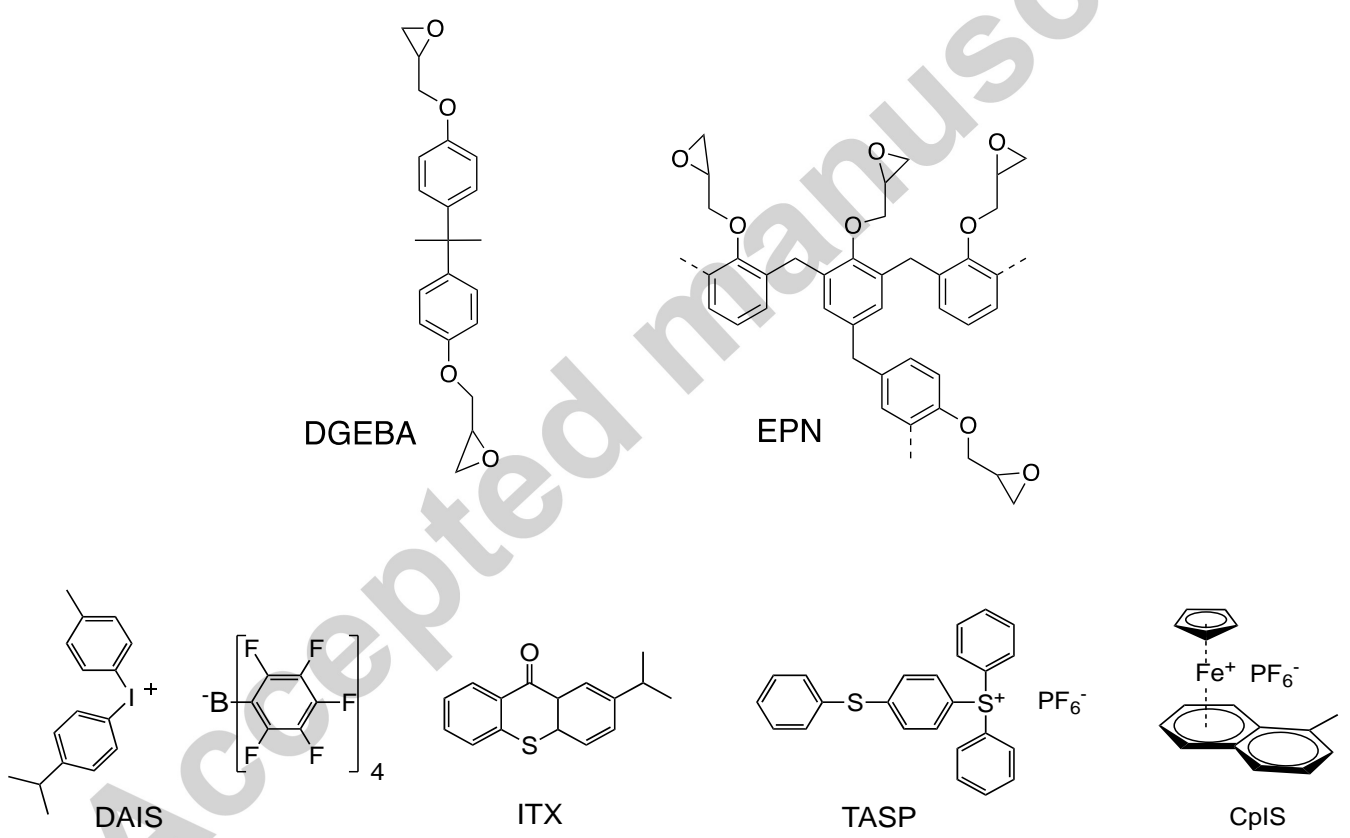

Scheme 1. Epoxy aromatic resins and cationic initiators used for the study.

\subsection{Polymerization procedure}

For preparing solid epoxy films, the liquid resins containing the required amount of initiator were cast onto Si wafers with bar coaters (10-20 mm thickness) and cured by exposure to the desired radiation source (150 keV EB lab accelerator (Advanced Electron Beams), $385 \mathrm{~nm}$ 


\section{ACCEPTED MANUSCRIPT}

LED array with an irradiance of $155 \mathrm{~mW} \mathrm{~cm}^{-2}$ (Hamamatsu), or a $150 \mathrm{~W}$ - 65000 lux halogen lamp (Philips)).

Bar samples of controlled dimensions (2 mm-thick and $5 \mathrm{~mm}$-broad, $40 \mathrm{~mm}$-long) -samples were poured into silicon molds and EB-cured with a pulsed accelerator (10 MeV Circe II Linac, $20 \mathrm{~kW}$, time-averaged dose rate of $15 \mathrm{kGy} \mathrm{s}^{-1}$ ). The dose was adjusted by changing the number of passes applied to the sample $(25 \mathrm{kGy}$ per pass for doses up to $100 \mathrm{kGy}$, followed by $50 \mathrm{kGy}$ per pass for higher doses).

\subsection{Characterization of the cured samples}

The monomer conversion $(\pi)$ was determined by near infrared spectroscopy performed with a Vertex 70 spectrometer (Bruker). The thermo-mechanical properties were determined with a TA Instruments Q800 Dynamic Mechanical Analyzer. The analyses were carried out on cured sample rods (17.5 mm-long, $10 \mathrm{~mm}$-broad, $2 \mathrm{~mm}$-thick) with a single cantilever clamp at 1 $\mathrm{Hz}$, a $30 \mu \mathrm{m}$ amplitude and a $3{ }^{\circ} \mathrm{C} \min ^{-1}$ ramp temperature. The temperature for the thermomechanical transition $\alpha\left(\mathrm{T}_{\alpha}\right)$ was determined from the position of maximum of the loss modulus E" and used for estimating the glass transition temperature $\mathrm{T}_{\mathrm{g}}$. Atomic force microscope (AFM) was used to investigate the network macrostructure of UV-cured epoxy resin on the DEN 431 resin containing 0.5 wt- $\%$ of DAIS and 0.2 wt- $\%$ of ITX as photosensitizer. The EPN resin containing DAIS and ITX was diluted at in butyl acetate (30 $\% \mathrm{w} / \mathrm{w})$. Two drops of this solution were cast on the Si wafer and the solvent was evaporated in an oven at $90^{\circ} \mathrm{C}$ for $5 \mathrm{~min}$. UV-initiated polymerization was conducted by exposing the samples to a UV-LED (LC-L3 36x36W, Hamamatsu) at $385 \mathrm{~nm}$ wavelength with an irradiance of $155 \mathrm{~mW} \mathrm{~cm} \mathrm{~cm}^{-2}$. Depending on the desired level of epoxy conversion, some samples were post-cured in an oven at $90^{\circ} \mathrm{C}$ for a controlled period of time.

Frequency-dependent dielectric measurements were performed from $10^{-1}$ to $10^{6} \mathrm{~Hz}$ at various constant temperatures between -80 and $+200^{\circ} \mathrm{C}$, in $10^{\circ} \mathrm{C}$ steps, using a Novocontro-l Alpha-a 


\section{ACCEPTED MANUSCRIPT}

high resolution dielectric analyzer. The measurements were performed on unconditioned (kept in ambient conditions for several days) $1 \mathrm{~mm}$-thick EB-cured DGEBA samples.

For the AFM measurements, two different imaging approaches were used. The evolution of the polymer network with the conversion values was studied by classical tapping imaging. Topographical and phase images were recorded using a Dimension 3100 microscope from BrukerNano. Silicon tips with nominal resonance frequency of $450 \mathrm{kHz}$ and nominal spring constant of 200 N.m-1 were used. The images were recorded in a soft tapping mode with a setpoint amplitude setup to $70-80 \%$ and a scan rate of $0.5 \mathrm{~Hz}$. The images were processed and treated using WSxM (Horcas et al. , 2007) and ImageJ 1.40g softwares.

Then, to see the evolution of the indentation modulus with irradiation, quantitative measurements were performed on a Multimode 8 AFM from BrukerNano using PeakForce QNM mode. Standard procedures from BrukerNano were used to choose the proper tip regarding the samples (Ohler, 2007). The deflection sensitivity was determined using a clear sapphire sample and is an average of 3 different measurements at the beginning and recalculated several times during the measurements. The spring constants of the cantilever were estimated using the thermal tuning and the Sader methods. The radius of each tip was determined before each set of measurements by using a proper calibration sample. For all samples, all the experiments were performed at room temperature and a controlled relative humidity of $40 \%$.

\section{Results and Discussion}

The objective of this work being a detailed and multiscale approach of network structure in radiation-cured epoxy networks, a good control of elaboration conditions is necessary. Our previous investigations were essentially based on DGEBA as a model compound. We have extended this approach to an epoxy novolac EPN, a commercial grade referred to as a semisolid resin having the structural features and properties gathered in Table 1. 


\section{ACCEPTED MANUSCRIPT}

Table 1. Comparison of the structural features and properties of epoxy resins used in this study.

\begin{tabular}{|c|c|c|c|c|c|}
\hline Epoxy resin & $\begin{array}{c}\text { Molecular } \\
\text { weight } \\
\left(\mathbf{g ~ m o l}^{-1}\right)\end{array}$ & $\begin{array}{c}\text { Average } \\
\text { functionality }\end{array}$ & $\begin{array}{c}\text { Epoxy content } \\
\left(\mathbf{m m o l ~ g}^{-1}\right)\end{array}$ & $\begin{array}{c}\mathbf{T}_{\mathbf{g}} \\
(\text { uncured) }\end{array}$ & $\begin{array}{c}\text { Viscosity } \\
(\mathbf{m P a} . \mathbf{s})\end{array}$ \\
\hline DGEBA & 340 & 2 & 5.6 & $-20^{\circ} \mathrm{C}$ & $8500\left(25^{\circ} \mathrm{C}\right)$ \\
\hline EPN & 453 & 2.8 & 5.7 & $18^{\circ} \mathrm{C}$ & $1400\left(52^{\circ} \mathrm{C}\right)$ \\
\hline
\end{tabular}

\subsection{Reactivity and control of network properties}

The preparation of well-defined samples requires a good control over curing kinetics and mastering the final conversion. Several composition and treatment factors exert a critical influence on the initiation and on the development of the polymerization process (Degrand et al. 2003).

Thin epoxy films (10 - $100 \mu$ m-thick) as well as plates (1-5 mm-thick) based on DGEBA or EPN were efficiently cured by exposition to EB radiation of convenient energy, $150 \mathrm{keV}$ and $10 \mathrm{MeV}$, respectively. The high efficiency of DAIS allows for satisfactory curing levels at a concentration low as $0,125 \mathrm{wt}-\%$ in thick samples. Polymerization exothermicity as well as the conversion of the incoming radiation into heat are of prime importance (Ranoux et al., 2012).

The kinetic profile measured by FTIR during the stepwise application of $150 \mathrm{keV} \mathrm{EB}$ treatments to a $10 \mathrm{~mm}$-thick film of EPN including $0.5 \mathrm{wt}-\%$ of DAIS is shown on Figure 1. 


\section{ACCEPTED MANUSCRIPT}
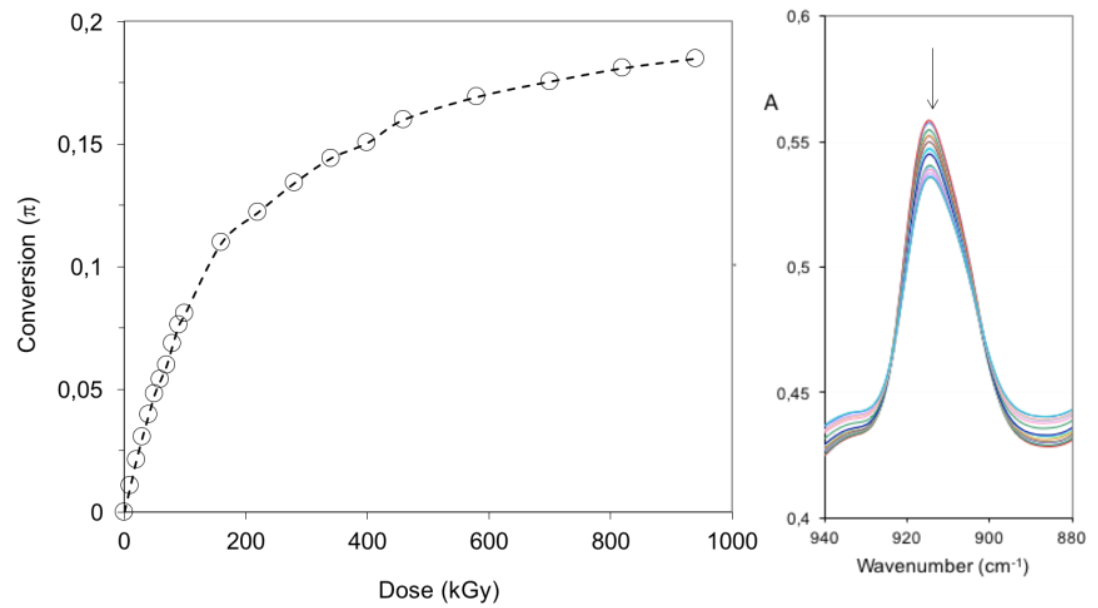

Fig. 1. Conversion profile measured by FTIR spectroscopy of a $10 \mu \mathrm{m}$-thick film of EPN sample with 0.5 wt- $\%$ of DAIS initiator submitted to increasing EB radiation doses (room temperature, $150 \mathrm{keV}, 10 \mathrm{kGy}$ per pass for doses up to $100 \mathrm{kGy}$, followed by $25 \mathrm{kGy}$ per pass for higher doses).

The conditions of this experiment with a fractionated exposure to the electron beam minimize the thermal effects with a fast dissipation of heat in the substrate (Defoort et al., 2001). This limits the development of the cross-linking polymerization that converts the epoxy resin into a glassy network. As soon as the glass transition temperature of the network under formation approaches the effective temperature of the sample, molecular diffusion and segmental motions are restricted. In the example of Figure 1, the fractional conversion of epoxy functions $(\pi)$ does not exceed 0.18 despite the extremely high dose applied to the sample.

A similar situation is observed when a thin DGEBA film including $0.5 \mathrm{wt}-\%$ of DAIS is submitted to a single dose of $45 \mathrm{kGy}$. The conversion measured just after irradiation is about 0.1 , but the polymerization further proceeds in the sample kept at room temperature with exclusion of moisture (Figure 2, curve a). The cationic polymerization proceeds to a much higher conversion level $\pi=0.5$ after several days. When the formulation includes 2 wt- $\%$ of sulfonium salt TASP and is exposed to $385 \mathrm{~nm}$ LED, the higher amount of initiator and thermal effects allow the conversion to reach higher levels $(\mathrm{P}=0.42$ and $\mathrm{P}=0.57$ at the end of the $1 \mathrm{~J} \mathrm{~cm}^{-2}$ and $5 \mathrm{~J} \mathrm{~cm}^{-2}$ exposures, respectively. Post-irradiation polymerization at room 


\section{ACCEPTED MANUSCRIPT}

temperature continues for about 1 to $2 \mathrm{~h}$, and the conversion finally reaching a plateau value close to 0.6 .

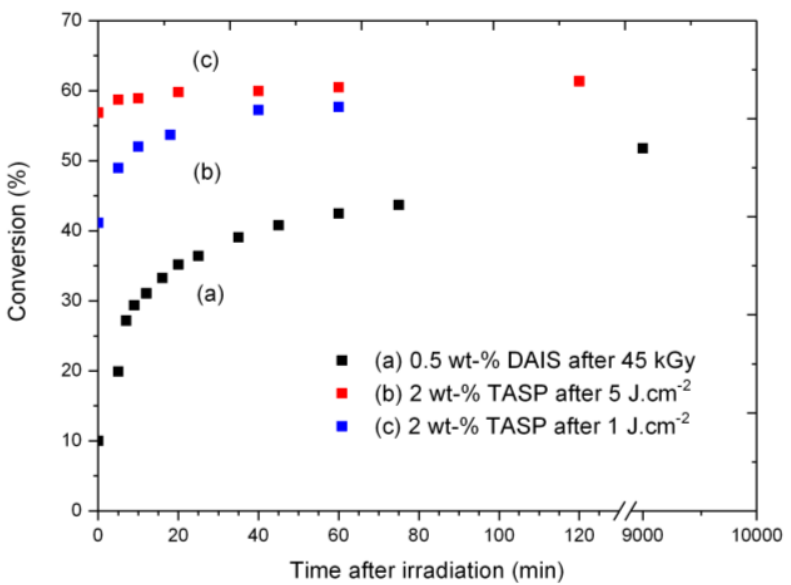

Fig. 2. Post-irradiation conversion profiles measured by FTIR spectroscopy for $10 \mu \mathrm{m}$-thick films of DGEBA kept at room temperature: (a) with 0,5 wt-\% DAIS initiator after $45 \mathrm{kGy}$ irradiation (150 kV), (b) $2 \mathrm{wt}-\%$ of TASP initiator after a $5 \mathrm{~J} \mathrm{~cm}^{-2}$ exposure to $385 \mathrm{~nm}$ LED, (c) $2 \mathrm{wt}-\%$ of TASP initiator after a $1 \mathrm{~J} \mathrm{~cm}^{-2}$ exposure to $385 \mathrm{~nm}$ LED.

When the resin is irradiated in the form of plates of thickness typically beteween 0.5 to $5 \mathrm{~mm}$, strong thermal effects occur during polymerization with peak temperatures as high 200$220^{\circ} \mathrm{C}$, depending on the efficiency of heat dissipation, on dose rate and dose increments (Ranoux et al., 2012). The experiments conducted with EPN containing $0.5 \mathrm{wt}-\%$ of DAIS in $2 \mathrm{~mm}$-thick molds were designed for obtaining fully cured samples, either by a single EB irradiation or by a combination with a post-treatment.

The data gathered in Table 2 indicate that a $20 \mathrm{kGy}$ irradiation is not sufficient to fully cure the samples, essentially because of too small rise in temperature during the irradiation which results in early vitrification of the network. Post-polymerization for $1 \mathrm{~h}$ at $200^{\circ} \mathrm{C}$ allows for completing the polymerization together with an increase in $\mathrm{T}_{\mathrm{g}}$ as measured from the position of the loss modulus E”. Irradiation at 30 and $50 \mathrm{kGy}$ yield samples with higher conversions ( $\pi$ $=0.96$ ) that can be further improved by the post-irradiation treatment. 


\section{ACCEPTED MANUSCRIPT}

Table 2. Influence of EB dose and of post-treatment on the epoxy conversion and on the glass transition temperature ( $1^{\text {st }}$ DMA run) of $2 \mu \mathrm{m}$-thick EPN-based bar samples $(0.5 \mathrm{wt}-\%$ DAIS).

\begin{tabular}{|c|c|c|c|c|c|c|}
\hline \multirow{2}{*}{$\begin{array}{c}\text { Treatment } \\
\text { (Dose, post-treatment) }\end{array}$} & \multicolumn{2}{|c|}{20 kGy } & \multicolumn{2}{|c|}{30 kGy } & \multicolumn{2}{|c|}{$50 \mathrm{kGy}$} \\
\hline & - & $1 \mathrm{~h} @ 200^{\circ} \mathrm{C}$ & - & $1 \mathrm{~h} @ 200^{\circ} \mathrm{C}$ & - & $1 \mathrm{~h} @ 200^{\circ} \mathrm{C}$ \\
\hline Epoxy conversion $(\pi)$ & 0.71 & ca. 0.99 & 0.96 & 0.99 & 0.96 & 0.99 \\
\hline $\mathrm{T}_{\mathrm{g}}\left({ }^{\circ} \mathrm{C}\right)$ & 44 & 177 & 175 & 178 & 177 & 182 \\
\hline
\end{tabular}

Based on a single pair of descriptors $\left(\pi, T_{g}\right)$, the cured samples the samples seem to have very close thermophysical characteristics. However, the presence of microheterogeneities and of long-lived cationic centers requires a deeper investigation.

\subsection{Heterogeneity revealed by DMA and DS relaxation spectra}

\section{DMA measurements}

Dynamic mechanical analysis is commonly used to investigate the morphology of polymers and composites. When used in favorable conditions, the technique is sensitive to low energy transitions which are not readily observed by differential scanning calorimetry. This holds particularly true for networks prepared by chain polymerization.

We have analyzed the influence of DAIS concentration on the thermomechanical relaxations in EB-cured DGEBA materials cured in the form of 1-mm thick plates by treatment with a dose of $2 \times 50 \mathrm{kGy}$. The samples treated in such conditions exhibit a high level of epoxy conversion $(0.92>\pi>0.98)$. On the left side of the main relaxation Tan $\delta$ peak observed in the spectra shown in Figure 3 a) at temperatures between 170 and $200^{\circ} \mathrm{C}$, a shoulder reveals a secondary transition that is commonly assigned to side group motions or local crankshaft or in amorphous homogeneous polymer systems. The strong dependence on the initiator concentration suggests a different interpretation based on the existence of domains with higher mobility where the degree of cross-linking or the presence of free monomer swelling a soft network where some polymer segments relax a temperature much lower than the main chains. Such an interpretation was supported by calorimetric analyses performed radiationcured diacrylate networks which allowed for description of the morphology by a twocomponent system (Krzeminski et al. 2010a). The pseudo-living behavior of the cationic 


\section{ACCEPTED MANUSCRIPT}

polymerization does not allow for such measurements. Indeed, the thermal ramp applied to the sample induces a resumption of the polymerization process which affects the sample structure and modifies its properties.

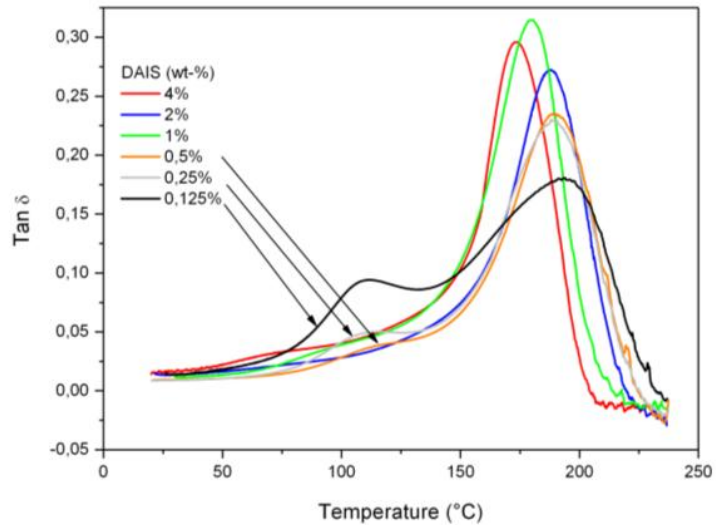

a)

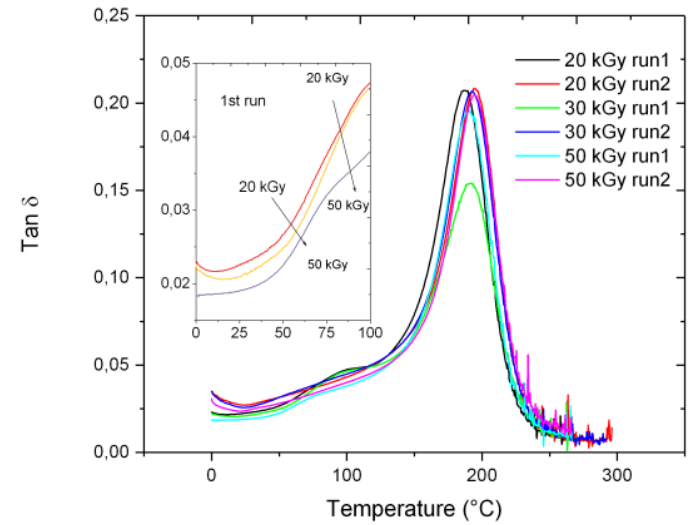

)

Fig. 3. Influence of DAIS concentration, and of thermal post-treatment on the thermomechanical relaxation in EB-cured (10 MeV) epoxy-based networks measured by DMA at $1 \mathrm{~Hz}$ : a) $1 \mathrm{~mm}$-thick DGEBA including 0.125 - 4 wt- $\%$ of DAIS initiator after 2 x $50 \mathrm{kGy}$ irradiation without post-treatment ( ${ }^{\text {st }}$ DMA ramp), b) 2 mm-thick EPN including $0.5 \mathrm{wt}-\%$ of DAIS initiator after 20,30 or $50 \mathrm{kGy}$ irradiation $\left(1^{\text {st }}\right.$ and $2^{\text {nd }}$ DMA ramps).

A similar behavior was observed with the EB or UV-vis cured DEN samples. We have selected here some results showing the influence of radiation dose (20, 30 and $50 \mathrm{kGy})$ applied to DEN mixtures including $0.5 \mathrm{wt}$ - $\%$ of DAIS (Figure $3 \mathrm{~b}$ ). The secondary relaxation shoulder observed at temperatures between 50 and $150^{\circ} \mathrm{C}$ decreases in intensity and its components seem to be shifted to higher temperature when the dose increases from 20 to 50 kGy. This supports the occurrence of chemical events associated with the evolution of the secondary transition and substantiates the interpretation given in the previous paragraph. Moreover, the spectra recorded during the second heating ramp show a decrease of the sub-Tg relaxation.

\section{Dielectric spectroscopy}

The dielectric permittivity and dielectric loss spectra of a $1 \mathrm{~mm}$-thick EB-cured DGEBA plates were recorded as a function of temperature. The plots of the dielectric loss are reproduced in Figure 4 for frequencies ranging from $10^{-1}$ to $10^{+6} \mathrm{~Hz}$. In the low temperature range (below room temperature), the $\beta$-relaxation, i.e. the secondary relaxation of polymer segments, is observed as a small shoulder. In the temperature range from 50 to $150^{\circ} \mathrm{C}$, the permittivity (not shown) and the dielectric loss both increase, especially at low frequencies, 


\section{ACCEPTED MANUSCRIPT}

and reach a maximum at around $120^{\circ} \mathrm{C}\left(\varepsilon^{\prime \prime}=40\right.$ at $\left.0.1 \mathrm{~Hz}\right)$. Here the process cannot be ascribed to the glass transition of the material as the thermodynamic $\mathrm{T}_{\mathrm{g}}$, measured by DSC, is between 150 and $180^{\circ} \mathrm{C}$, implying that the dielectric loss maximum is beyond this temperature for the investigated frequency range. A concomitant increase of permittivity and loss at low frequency is encountered when ionic species are involved in the conduction mechanism. As electrodes are generally blocking for ionic species, ionic conduction gives rise to charges accumulation adjacent to the electrodes under sufficiently low frequency. A more complete analysis of the loss process in in terms of ion transport is proposed elsewhere (Vissouvanadin et al., 2016).

In the dielectric $\tan \delta$ plot of Figure $4 \mathrm{~b}$ ), the presence of two relaxation processes, labeled $\rho$ and $\rho^{*}$, is clearly observed. Both relaxation processes appear related to the motion of charges for the reasons stated above. It is tempting here to associate the lower temperature one $(\rho)$ to the lower temperature mechanical relaxation process of Figure 3. Though the dielectric loss peak may be due to ionic transport, the triggering mechanism for ion motion could be the onset of chain segment motion of high mobility. The dielectric response would be a complex process involving residual ion density, the heterogeneity of the microstructure and the degree of curing of the matrix.

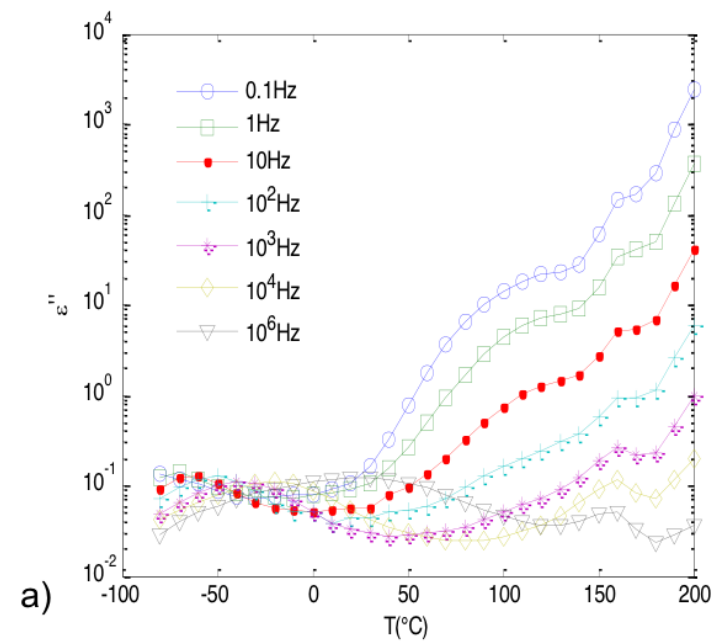

Fig. 4. Dielectric spectrograms (dielectric loss $\varepsilon "$

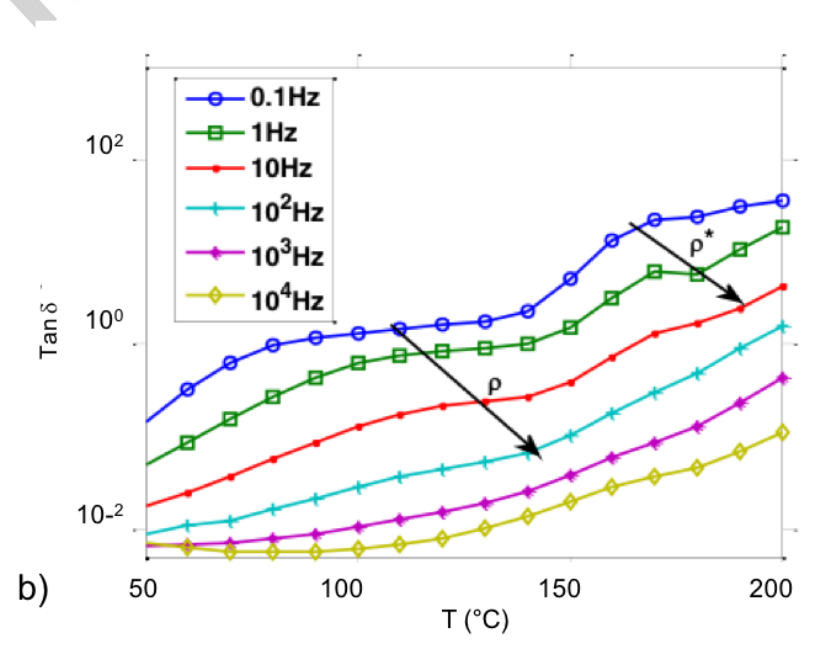
(a) and $\tan \delta(b))$ revealing the dielectric relaxation at low frequency in $1 \mathrm{~mm}$-thick EB-cured DGEBA samples containing $1 \mathrm{wt}-\%$ DAIS (100 kGy, post-curing 90 min at $\left.180^{\circ} \mathrm{C}\right)$.

In order to evidence at the proper dimension scale, the effects interpreted in terms of microheterogeneity, we have managed to use near field techniques offering the possibility to 


\section{ACCEPTED MANUSCRIPT}

gain quantitative information on networks formed from the same single precursors (DGEBA or $\mathrm{EPN})$. 


\subsection{AFM imaging and measurements}

A first series of 5 films based on DGEBA monomer mixed with a suitable initiator was prepared for imaging their surface with the methodology used previously (Krzeminski, 2010b). The polymerization was either induced by EB irradiation with compositions including DAIS or under UV-visible light with compositions including CpIS in order to achieve various level of conversion. The typical roughness of the films surface was typically below $0.35 \mathrm{~nm}$ over a probed area of $300 \times 300 \mathrm{~nm}^{2}$. The phase contrast images reproduced in Figure 5 a) reveal significant variations of the interactions of the tip interacting in the tapping mode, as a function of local viscoelastic interactions and of adhesion forces. The whiter zones correspond to the hard domains which are not correlated to the sample topology with a very smooth surface. By applying appropriate image treatments, with reasonable threshold values, the pictures of Figure $5 \mathrm{~b}$ ) are obtained with black domains corresponding to the rigid clusters contrasting well from the softer background. The pseudo-living character of cationic polymerization of DGEBA as well as the tackiness of the surface at low levels of conversion $(\pi)$ did not allow to analyze with a satisfactory level of confidence samples with $\pi<0.4$. However, over the conversion range covered by the 5 samples, the global coverage of black zones in the pictures increases, as expected, with conversion.

a)

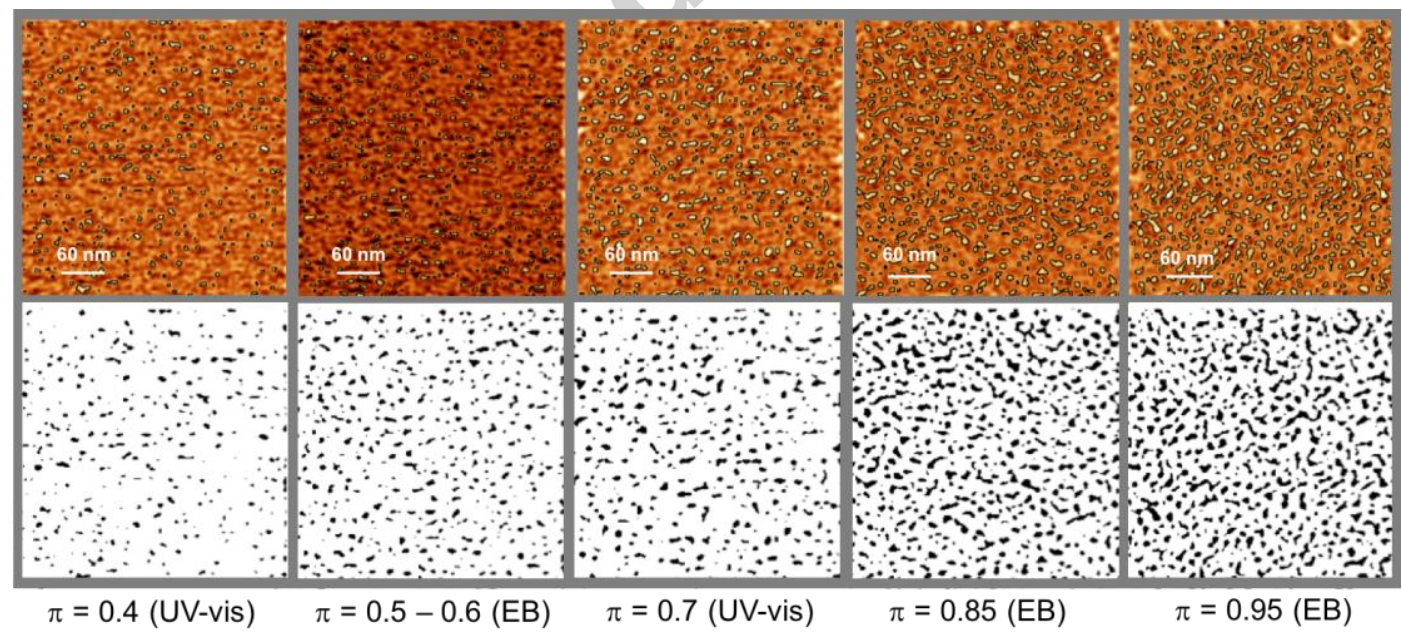

Fig. 5. Phase images as obtained by tapping mode AFM for radiation-cured DGEBA networks $\left(300 \mathrm{x} 300 \mathrm{~nm}^{2}\right.$ area) with conversions ranging from $\pi=0.4$ to $\pi=0.95$, as recorded (a), after image processing and thresholding (b). 


\section{ACCEPTED MANUSCRIPT}

The dimensions of the clusters were measured in terms of Feret's diameter, the larger dimension observed for a dark island in the plane of the image, and in terms of area. The quantification affords interesting information supporting the scenario proposed previously for the free radical cross-linking polymerization of aromatic diacrylates (Krzeminski, 2010b). The initiation proceeds locally and forms small gel domain which grow (i) in number, as the number of initiation sites increase with the radiation dose, and (ii) in size until vitrification limits the development and the internal cross-liking with the nanoclusters. Once the percolation threshold is reached, the clusters can merge by polymerization in the soft domains at their interface. The evolution of the Feret's diameter distributions shown in Figure 6 a) indicates that initial clusters $(\pi=0.4)$ have a typical cross-section of $5-10 \mathrm{~nm}$ which is gradually shifted to higher values with an increasing dispersity. The distribution of the area values for the clusters varies accordingly (Figure $6 \mathrm{~b}$ ), with a dramatic loss of circularity.

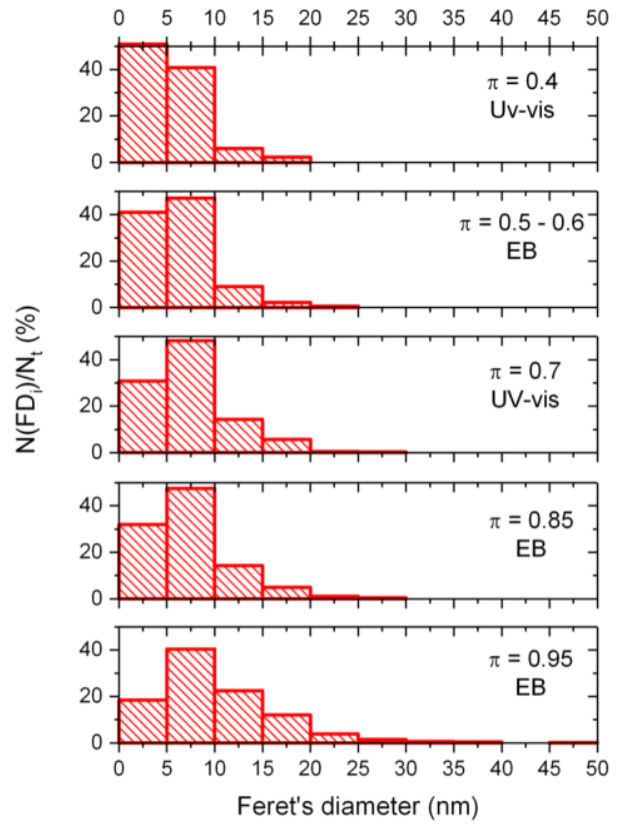

a)

Fig. 6. Histograms representing the conversion dependence of geometrical parameters of rigid clusters probed by tapping mode AFM in radiation-cured DGEBA samples: a) population of clusters as a function of the Feret's diameter (FD), and cluster area (A).

The plot of Figure 7 show the continuous increase of the mean Feret's diameter as the network consolidation takes place in the interstitial domains. At high conversion $(\pi=0.95)$, 
the monolithic material still exhibits local variations of cross-linking density, in agreement with the macroscopic observations obtained from DMA and DS.

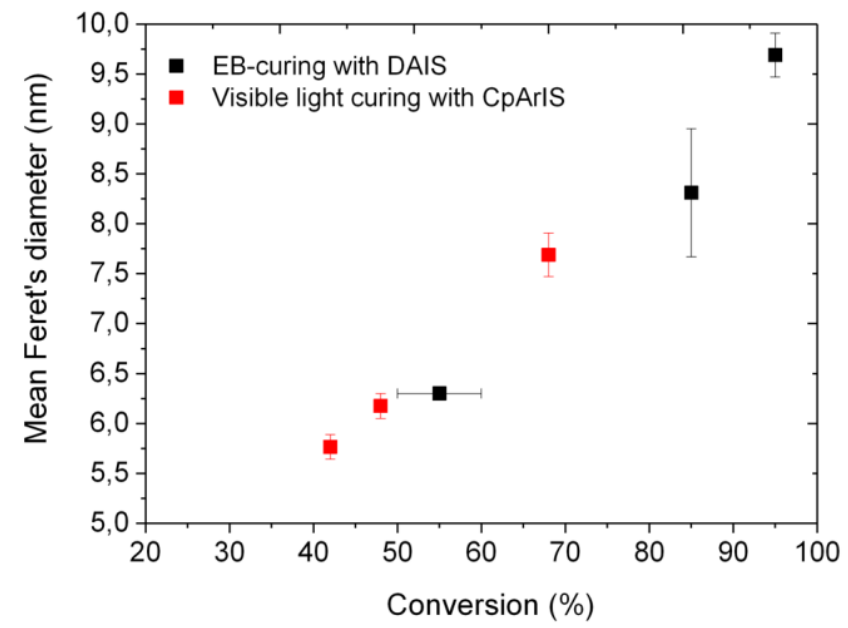

Fig. 7. Evolution of the average Feret's diameter of rigid clusters probed by tapping mode AFM in radiationcured DGEBA sample with various degrees of conversion.

With the advent of new probing AFM techniques with measurement of the peak normal force allowing for quantitative characterization of mechanical properties at small dimensions, including modulus, adhesion, dissipation, and deformation, while simultaneously imaging sample topography, we have extended our investigation to the epoxy novolac (EPN) which is a soft by solid material in the uncured state at room temperature, thus reducing the influence of adhesion forces for the low degrees of conversion. A series of 5 samples was prepared as described in Table 3, with a fractional conversion $\pi$ ranging from 0.17 to 0.79 .

Table 3. Curing conditions and final conversion for the $10 \mu \mathrm{m}$-thick EPN-based films prepared for AFM characterization in QNM mode (0.5 wt-\% DAIS, 0.2 wt-\% ITX)

\begin{tabular}{|c|c|c|c|c|c|}
\hline Sample & 1 & 2 & 3 & 4 & 5 \\
\hline Duration of LED irradiation at $385 \mathrm{~nm}(\mathrm{~s})$ & 75 & 100 & 25 & 50 & 500 \\
\hline Duration of post-curing at $90^{\circ} \mathrm{C}(\mathrm{min})$ & - & - & 3 & 10 & 10 \\
\hline Epoxy conversion $(\pi)$ & 0.17 & 0.25 & 0.53 & 0.67 & 0.79 \\
\hline
\end{tabular}




\section{ACCEPTED MANUSCRIPT}

Topographic imaging of the cured EPN films confirmed the smoothness but with a significant and continuous enhancement of their roughness with increasing conversion. The plots of Figure 8 show the conversion-dependence of topography and of deformation parameters averaged out of nine images per sample type (triplicated measurements made on three distant spots per sample). The values displayed in figure 8 were averaged out of nine $(300 \times 300$ $\mathrm{nm}^{2}$ ) images per sample type (triplicated measurements made on on three distant spots per sample). The deformation under the tip decreases as the cross-link density increases, the value for Young's modulus increasing concomitantly. It is noteworthy that the $2 \mathrm{~mm}$-tick EPN samples prepared with the same conversion level $(0.7<\pi<0.9)$ by EB-curing exhibit a glassy Young's modulus of about 2800-3000 MPa, a value very similar to the one obtained by nanomechanical measurements.
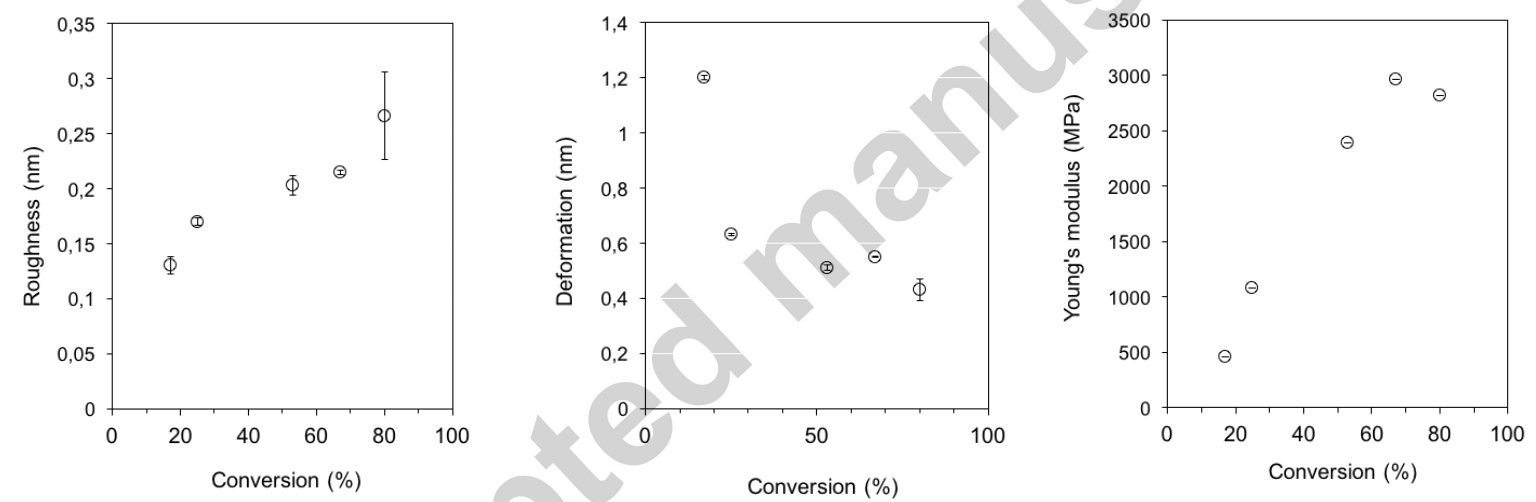

Fig. 8. Quantitative nanomechanical characteristics probed by AFM on $10 \mu \mathrm{m}$ thick UV-cured EPN films containing DAIS $(0.5 \mathrm{wt}-\%)$ and ITX $(0.2 \mathrm{wt}-\%)$ after irradiation and optional post-treatment at $90^{\circ} \mathrm{C}$.

These results encourage us to further examine the influence of initiator's concentration and of the nature of the counter anion on the evolution of networks microstructure and on their nanomechanical properties. A better knowledge and understanding of the build-up of the networks and late of the consolidation of the resulting monolithic materials would be useful in several potential applications of the epoxy chemistry, such as performance composites and nanolithography. On-going studies are investigating at lower scales the impact of the nanoheterogeneities evidenced in tapping mode on the local changes in mechanical properties. 


\section{Conclusions}

Various initiators suitable for the radiation-induced cationic polymerization were used for curing two model resins based on bis-phenol A and on a novolac. The influence of initiator nature and concentration as well as of treatment parameters were determined for elaborating films or plates with well-controlled conversion level and $\mathrm{T}_{\mathrm{g}}$. Relaxation measurements performed by DMA and DS have confirmed the occurrence of sub-Tg relaxations which are very sensitive to content in initiator and to processing conditions (dose and post-irradiation heating).

Based on AFM imaging, the polymerization scenario involving nucleation, growth and aggregation of nanoclusters that we proposed previously for diacrylates is confirmed, yet with the specificities of cationic mechanisms of initiation and propagation.

Further investigations are underway to determine the effect of various parameters on the network microstructure considering more specifically the influence of the initiator nature and of its concentration on the build-up of local mechanical properties.

Acknowledgements. This work was conducted in part in the frame of project ICIP funded by the French National Research Agency (supported by Cluster Materalia). Financial support by Conseil Regional Grand Est, MENESR and EU-FEDER Programme (CPER Projects PlAneT and Nano'Mat) is gratefully acknowledged. The authors are grateful to the French - Polish programme Marie Sklodowska-Curie for supporting the stay of MW at ICMR.

\section{References}

Bowman, C. N.; Kloxin, C. J., 2008. Toward an enhanced understanding and implementation of photopolymerization reactions. AIChE J., 54, 2775-2795.

Coqueret X., 2008. Obtaining high performance polymeric materials by irradiation, In: "Radiation Chemistry. From basics to application in material and life sciences", M. SpotheimMaurizot, M. Mostafavi, T. Douki, J. Belloni (Eds), Chapter 9, EDP Sciences / L'Actualité Chimique, Les Ulis.

Crivello, J. V., 1999. UV and electron beam-induced cationic polymerization. Nucl. Instrum. Methods Phys. Res., Sect. B., 151, 8-21. 


\section{ACCEPTED MANUSCRIPT}

Crivello, J. V., Dietliker, K., Bradley, G., 1999. Photoinitiators for free radical, cationic and anionic photopolymerization. In: "Chemistry and technology for UV and EB formulation for coatings, inks and paints, formulation", 2nd Edition, Wiley, New York.

Defoort, B., Defoort, D., Coqueret, X. 2001. Electron-beam initiated polymerization of acrylate compositions, 2. Simulation of thermal effects in thin films. Macromol. Theor. Simul., 9, 725-734.

Defoort, B., Lacour, D., Coqueret, X., 2006. Rigidification of structures to be deployed by inflating, particularly for use in space. PCT Patent 2006/043009.

Degrand, H., Cazaux, F., Coqueret, X., Defoort, B., Boursereau, F., Larnac, G., 2003. Thermal effects on the network structure of diglycidyl ether of bisphenol-A polymerized by electron-beam in the presence of an iodonium salt. Radiat. Phys. Chem., 68, 885-891.

Di Lorenzo, F., Seiffert, S., 2015. Nanostructural heterogeneity in polymer networks and gels. Polym. Chem, 6, 5515-5528.

Dušek, K., 1971. Inhomogeneities induced by crosslinking in the course of crosslinking copolymerization, In: "Polymer Networks Structure and Mechanical properties", A. J. Chompff, et al. (Eds), Springer, Berlin.

Dušek, K.; Galina, H.; Mikes, J., 1980. Features of network formation in the chain crosslinking (co)polymerization. Polym. Bull., 3, 19-25.

Ferry, M., Ngono-Ravache, Y., Aymes-Chodur, C., Clochard, M. C., Coqueret, X., Cortella, L., Pellizzi, E., Rouif, S., Esnouf, S., 2016. Ionizing radiation effects in polymers. In: "Reference Module in Materials Science and Materials Engineering". Saleem Hashmi (editorin-chief), Elsevier, Oxford, 1-28.

Horcas, I., Fernández, R., Gómez-Rodríguez, J.M., Colchero, J., Gómez-Herrero, J., Baro, A.M., 2007. WSXM: a software for scanning probe microscopy and a tool for nanotechnology. Rev. Sci. Instrum., 78, 13705-13708.

Krzeminski, M., Molinari, M., Troyon, M., Coqueret, X., 2010. Calorimetric characterization of the heterogeneities produced by the radiation-induced crosslinking polymerization of aromatic diacrylates. Macromolecules, 43, 3757-3763.

Krzeminski, M., Molinari, M., Troyon, M., Coqueret X., 2010. Characterization by atomic force microscopy of the nanoheterogeneities produced by the radiation-induced crosslinking polymerization of aromatic diacrylates. Macromolecules, 43, 8121-8127. 


\section{ACCEPTED MANUSCRIPT}

Ohler, B., 2007. Practical advice on the determination of cantilever spring constants. Bruker's Application notes 94.

Przybytniak, G., Nowicki, A., Mirkowski, K., Stobiński, L., 2016. Gamma-rays initiated cationic polymerization of epoxy resins and their carbon nanotubes composites. Radiat. Phys. Chem., 121, 16-22.

Ranoux, G., Molinari, M., Coqueret, X., 2012. Thermo-mechanical properties and structural features of diglycidyl ether of BIS phenol a cationically cured by electron beam radiation. Radiat. Phys. Chem., 81, 1297-1302.

Sangermano, M., 2012. Advances in cationic photopolymerization. Pure Appl. Chem., 84, 2089-2101.

Vissouvanadin, B., Teyssedre, G., Le Roy, S., Laurent, C., Ranoux, G., Coqueret, X., 2016. Dielectric and electrical properties of radiation-cured epoxy materials, IEEE Trans. Dielectr. Electr. Insul., 22, 1142-1150.

Yağci, Y., Reetz, I., 1998. Externally stimulated initiator systems for cationic polymerization. Prog. Polym. Sci., 23, 1485-1538.

\section{Highlights}

- Thermal conditions of irradiation are crucial for the radiation-cured epoxy networks

- DMA and DS reveal sub-Tg relaxation associated with microheterogeneities

- Tapping mode AFM allows for the visualization of nanoclusters percolation

- QNM AFM shows the build-up of local Young's modulus as a function of conversion 